\title{
Should public health respect autonomy?
}

Spencer A Hall New Mexico, USA

\section{Author's abstract}

This paper suggests that public health, due to its community orientation, may be ignoring certain ethical principles namely the rights of individuals and communities to self-determination. The expectation of individual rights as a member of a community is reviewed and the additional right of a community for self-determination is proposed. The influences on ethical evaluations by the legal and economic environments are suggested, using US examples. The conclusion argues that as the focus of health-care delivery changes, it will become more important to consider these questions of group ethics.

Public health is aimed at improving the health of communities. The ways in which this is attempted vary, but are often aimed at improving individuals' health in the community, thus giving the entire community a net benefit. Very few of these changes may be accomplished without addressing individual behaviours. Any potential interference with individuals raises certain ethical considerations considerations which are not routinely addressed by public health, a fact which has recently provoked both comment and criticism (1).

An explanation for this lies in the different training and focus of public health practitioners. They are trained to promote the aggregate health of a population group, rather than deal with individuals and their diseases (2). By concentrating on groups, it is easy to ignore rights of individuals. Of course, the focus of public health practitioners should be the health of the community, but they should take into account other factors such as ethics when they plan public health interventions. It is only recently, as individual rights are being recognised more commonly, that the question of public health practitioners' respect for individual rights should be raised and the logical extension of analogous rights to the community be recognised.

In considering the moral questions involved in any public health intervention, there are two primary areas which must be recognised. The first is what the nature

\section{Key words}

Autonomy; community; ethics; public health. of a given community implies as to the rights of its members. The second is what rights, if any, the community has on its own. Each of these has a unique status with regard to public health actions. The individual rights of each member of a community should be respected in accordance with the norms of that community. The community itself should be granted self-determination.

\section{Individuals' rights in a community}

There are a couple of conceptualisations of community which imply different degrees of rights for their members (3). Communities all exist based on some degree of an underlying social contract - withour agreement, a fundamental notion of obligation and organisation, there cannot be a community. Where communities differ is in the nature of these obligations. One view (4) holds that communities are merely groups of individuals held together by the duty of refraining from harm to others. In this type of society, known as a minimalist community, personal freedoms are of the highest importance and, with the exception of harming others, non-regulated. In this type of community, it would be difficult for public health to justify many interventions that are now commonplace. Many diseases are of little direct harm to others, therefore they should be only of personal, rather than community, concern. A minimalist community lacks moral power to dictate behaviours which are matters of personal concern (5). This view of community is in the minority, and its entire philosophy has been criticised as leading to moral chaos (6).

A more common definition of community holds that communities are more complex than outlined above. In addition to duties of not harming others, elements of personal freedom may be given in exchange for other goods; by purchasing elements such as caring and beneficence, individuals strengthen the ties that form their community. These communities are more likely to strive to meet basic human needs such as food and housing, as well as having the moral inclination, and experience, to act and to ask their individuals to act for the increased benefit of the group as a whole. This inclination is not absolute however; although certain aspects of personal autonomy may have been yielded to the group (7), many elements of self-determination 
remain. Thus, any intervention for the good of the community must still be weighed against a possible insult to personal autonomy. Individuals may still retain the right to refuse to act in accord with public health demands.

In some instances, it seems that individuals make health-care decisions which are 'unwise' when viewed impartially. In these cases, it seems that it would be appropriate for the community to dictate the actions/ choices of its members. After all, it could only benefit the community to help its individual members. The behaviour of the group in dictating the actions of its members is commonly called paternalism - 'The interference with a person's liberty of action justified by reasons referring exclusively to the welfare, good, happiness, needs, interests or values of the person being coerced' (8). Paternalistic interventions, not limited to public health measures, are an area of hot debate in modern ethics. There are those who believe that any affirmation of paternalism would 'justify the imposition of a Spartan-like regime requiring rigorous physical exercise and abstention from smoking, drinking, and hazardous pastimes' (9). Additionally, paternalism is unique in being absolutely prohibited in the philosophy of J S Mill (10), unlike his mere conditional prohibitions against lying and other behaviours. A less strict approach holds that paternalistic influence may be justified under certain conditions. Some believe this is because there is tacit prior consent to this type of intervention by anyone who is a member of the society (11), indeed, allowing this interference may be a price of membership. Others hold that interventions are justified only if the rational subject would consent after the intervention proved to be beneficial (12). Both of these views are ultimately based on respect for autonomy, however, because the very notion of consent implies that the individual's wishes are considered. True paternalism, in the nature of a parent caring for the best interests of a child or the State for an incompetent, does not rely on consent. It is based in beneficence and must rest on moral justification of the action (13). This justification is based on finding that the intervention is necessary to prevent a grave danger to the individual by the means least burdensome to that individual's autonomy.

Thus, regardless of our conceptualisation of community or paternalism, individual autonomy remains to some degree. The degree will depend on the community. For example, members of the military usually give up much more of their autonomy than do students in a college. This remaining right to selfdetermination should be addressed when any public health intervention which impinges on personal freedoms is considered. There is no evidence that this is now being done by public health planners, even though there is increasing respect for personal autonomy by doctors caring for individual patients (14) and US federal legislation mandating hospitals to do so (15). Granted, it is easier to consider the personal autonomy of a single patient than many simultaneously, but mere difficulty should not be used as an excuse for depriving individuals of their rights.

There is one strong argument which is sometimes used against community respect for autonomy - the notion that an individual's right to respect is abrogated by virtue of that individual's responsibility for causing the problem in the first place (16). In other words, he or she may be punished for 'bad' behaviour, such as a self-inflicted illness, by loss of certain rights such as autonomy. Cigarette-smoking provides many examples of this sort of debate. The problem with this reasoning is that a person is not always solely responsible for his/her own behaviour:

'To assert that individuals have had a part, even a good part, in causing their illness and deriving from this a loss of communal responsibility to come to their aid are two different things ... genetic predisposition, social circumstances, early conditioning, educational focus, environmental pressures, and many more, play a vital role not only in determining what habits we shall assume, but likewise condition the way we look at (and at times, the way we resist or fail to resist) those habits' (17).

Since much of what people are depends on the community in which they are raised, then the्e community cannot divorce itself from subsequent responsibility for persons' disabilities. The community, rather than stripping individuals? autonomy rights, should owe them at least this level of consideration.

\section{Community rights}

In addition to individual autonomy, there is another area of rights to be considered. This is that of respect for the community. One might also deem this autonomy of a sort; autonomous actions are those actions made with intention, knowledge and understanding, and free from controlling influences (18). There is no clear precedent for 'community autonomy', but the right of a group of individuals collectively to determine their group's actions is arguably an appropriate extension of personal rights. Communities as well as individuals may wish to make choices about their behaviours that outsiders deem unwise. Individuals have this right, whether communities presently do, is less clear.

Consideration of the rights of the affected community makes pragmatic as well as moral sense. Conflict with community autonomy is likely to occur where identification of a public health 'problem' is made outside the community and attempts to rectify the problem are also directed from outside. Without input and agreement from the target community, it is not surprising that these types of interventions often fail (19).

A possible foreshadowing of respect for community autonomy is seen in the blossoming of communityhealth-decision organisations which are trying to move 
some health care concerns from being individualistic to more communitarian (20), though what has been seen to date is prompted more by pragmatic and economic concerns than respect for autonomy. In fact, some have gone so far as proposing 'a move from individual consent to what some have called "informed community consent" by granting local communities the ethical and political authority to articulate and to enact their own conception of the good' (21). There is no question that in order to do this community autonomy must be recognised; the very notion of informed consent requires full autonomy for the actor giving consent (22).

\section{Legal environment}

Unfortunately, perhaps, moral arguments are not able to be separated from the legal environment in which they may apply. Communities all have a structure of formal rules which may dictate behaviour, regardless of the ethical impact. A brief discussion of the United States legal philosophy with regard to the issues discussed above will demonstrate this point. The legal outlook is similar in the other common law countries; the Public Health (Disease Control) Act of 1984 in Great Britain espouses a similar approach towards public health problems to that outlined initially below.

The current US legal position on public health stems from a 1904 case in which the Supreme Court ruled that a State could fine individuals who did not comply with a vaccination order (23). Although this is an old case, it is very much alive, because it is the only case clearly to set forth a discussion of what limits may be put on public health interventions. It is still widely cited in this context. This case has been used over the years to justify governmental intrusion upon personal autonomy when there is a 'compelling interest' (24). The question of when a public health intervention reaches the level of a compelling interest is open to debate, but it would likely do so when legislation is required to correct some serious health threat. Quaratine laws are a good example of this sort of legislation.

It is interesting however, that this landmark-case reflects an early awareness of the tension between paternalism and individual rights:

'There are manifold restraints to which every person is necessarily subject for the common good. On any other basis, organised society could not exist without safety to its members' (25).

\section{is contrasted with}

'There is, of course, a sphere within which the individual may assert the supremacy of his own will, and rightfully dispute the authority of any human government, - especially of any true government existing under a written constitution, - to interfere with the exercise of that will' (26).
This may have been prophetic. In the US, the recent legal trend has increasingly emphasised the importance of personal decisions in health care. This has extended as far as decriminalising suicide and allowing terminally-ill patients to order the withdrawal of their life-support (27). The right to refuse medical treatments easily extends to those modalities used commonly in public health interventions, for example screening tests.

The current AIDS epidemic is demonstrating a continued turnaround in legal philosophy. Many States in the US have enacted laws granting confidentiality to individuals who are infected with AIDS. This runs directly contrary to established epidemic treatment which depends on identification of disease-carriers and explicitly recognises the empowerment of individual rights to the detriment of public health.

\section{Economic environment}

In addition to the legal environment, economic factors may increasingly influence health care decisions by raising issues of distribution and access in a time of limited resources. The economic pressures on all health care decisions will only increase in the future.

'It is now almost universally believed that the resources available to meet the demands for health care are limited ... We as a nation [US], will have to think veryen carefully about how to allocate the resources we are: willing to make available for health care' (28).

Again, a couple of brief examples drawn from the US may clarify this reasoning.

The treatment of hypertension (HTN) was not found to pay for itself in savings from heart attack or stroke (29). Additionally, the cost of from $\$ 10,000$ to $\$ 20,000$ per quality-year-of-life for treatment was questioned as a reasonable price to pay. Similarly, it does not seem appropriate to screen individuals for colon cancer (30), although this is one of the most frequent neoplasms. These conclusions raise serious ethical questions that directly impact public health practitioners (31). Now it would seem that another factor the practitioner must weigh in the decision to undertake a public health intervention is a costeffectiveness determination. It could be argued that it would be unethical to waste limited resources by doing low-yield interventions.

Public health interventions, especially in the areas of health promotion and disease prevention, are usually more cost-effective in the long run than individual patient-care advances. It is likely that we will be seeing more of them in the future. If they are to succeed in an environment of increasing awareness of autonomy, both personal and community, even efficient interventions must deal with their ethical impact.

\section{Conclusion}

Many medical practitioners deal with ethical questions 
routinely. This is not the case with public health practitioners, but the situation is likely to change. There will be two main causes for this.

The first is that the continuing increase in respect for individual autonomy will force public health practitioners to become more aware of the impact any of their interventions will have on individuals, and to allow individuals more freedom in anticipation. An increased awareness of personal autonomy may translate to an increase in interest among individuals in their own health care, of which public health is an important part.

This increase in personal freedoms is not without bounds. Both the legal and economic environment will apply pressure on the individual to conform in behaviours which may threaten others in the community. For example, individuals still have the right to smoke, but this occurs at the cost of increased insurance rates, and, most significantly, increased chance of illness or death. Additionally, investigating what responsibilities an individual may have towards his or her community by accepting his or her role as a citizen may represent a new way of balancing individual autonomy and social responsibility (32).

The second factor forcing an awareness of selfdetermination on public health will be the increasing presence of communities as actors in health care delivery. Formerly, communities were merely targets for public health interventions, but in the future they will be more active consumers. The situation is foreseen by a leading US bioethicist, Daniel Callahan, co-founder of the Hastings Center, who writes:

'We will not, I believe, be able to work out the problems of our health care system unless we shift our priorities and bias from an individual-centered to a community-centered view of health and human welfare. We cannot, and ought not to give up a respect for individual needs and dignity, but we can place them within a social perspective and allow that to color our understanding .... At present we ordinarily begin by asking just what it is that individuals need for their good health; if there are communal concerns, they are put in a subordinate position. I want to reverse that priority - to begin with the communal needs and to put individual needs, rights, and interests in the subordinate position. It is the latter that must act as restraint upon the former, not the other way around as at present' (33).

If communities will be taking the primary role in future health care, then they should be granted autonomy as a recognition of the implications of this role.

Public health has an enviable history. Disease prevention strategies have done more to promote health than any treatment regimen yet discovered. As times change however, it is appropriate to ask if public health is currently recognising the rights of selfdetermination possessed by the individuals and communities on which its actions impact.
Perhaps an early recognition of the importance of these issues is reflected in a numerical model developed to prioritise public health problems in times of limited resources (34). This model incorporates community and individual acceptance of the proposed intervention into the ranking in a way that will cancel any and all other considerations supporting the intervention if it is merely not wanted.

Let us hope that this awareness of the importance of self-determination by public health practitioners will continue and increase.

Spencer A Hall, $M D, \mathcal{F D}$, is engaged in the practice of emergency medicine and consults on legal issues related to health, in Lincoln, New Mexico, USA. He is licensed to practise both law and medicine.

\section{References and notes}

(1) Skrabanek P. Why is preventative medicine exempted from ethical constraints? Fournal of medical ethics 1990; 16: 187-190.

(2) McBeath W H. Executive director of the American Public Health Association; testimony before the subcommittee on health and the environment of the Committee on Energy and Commerce of the US House of Representatives, 1981 Jul 29.

(3) Loewy E H. Communities, self-causation and theㅇ natural lottery. Social sciences and medicine 1988; 26: 1133-1139.

(4) Engelhardt H T. The foundations of bioethics. New York: Oxford University Press, 1986

(5) The indirect cost to the minimalist community for support of chronic-disease patients is not an issue, as the connection of harm to others is vague and the community owes no duty of care to individual members.

(6) Callahan D. Minimalist ethics. Hastings Center report 1981; Oct 11, 5: 19-25.

(7) Childress J F. The place of autonomy in bioethics. Hastings Center report 1990; Jan/Feb, 20 (1): 12-13.

(8) Dworkin G. Paternalism. The monist 1972; 56: 65.

(9) Harris R. Private consensual/adult behavior: the requirement of harm to others in the enforcement of morality. UCLA law review 1967; 14: 585n.

(10) See reference (8): 70

(11) See reference (8): 64-84.

(12) Carter R. Justifying paternalism. Canadian journal of philosophy 1977; 7: 133-145.

(13) Beauchamp T L, Childress J F. Principles of biomedical ethics. New York: Oxford University Press, 1989.

(14) This interest has been highlighted in recent years by increasing court recognition of autonomy rights, and is evidenced, for example, by patients' bills of rights.

(15) The Patient Self-Determination Act (PSDA) of 1990, included in the Omnibus Budget Reconciliation Act (OBRA) of 1990.

(16) Dworkin G. Taking risks, assessing responsibility. Hastings Center report 1981; Oct 11, 5: 26-31.

(17) See reference (3): 1138.

(18) See reference (13): 69.

(19) Geiger H J. Community control - or community conflict. National Tuberculosis and Respiratory Disease Association bulletin 1969; 55: 4-11.

(20) Jennings B, ed. Grassroots bioethics revisited: health care priorities and community values (a collection of 
summary articles). Hastings Center report 1990; Sept/Oct 20, 5: 16-23.

(21) Emanuel E J. A community view of care for incompetent patients. Hastings Center report 1987; Oct/Nov 17, 5: 1520.

(22) See reference (13): 74-85.

(23) Jacobson v Massachusetts 197 US 11, 1904.

(24) See, for example: Thornburgh v American College of Obstetrics and Gynecology 476 US 747, 808-809, 1985.

(25) 197 US 11, 26.

(26) 197 US 11, 29.

(27) See, for example: Quinlan 355 A2d 647 and subsequent cases.

(28) Weinstein M C, Stason W B. Allocating resources: the case of hypertension. Hastings Center report 1977; Oct 7, 5: 24-29.
(29) Weinstein M C, Stason W B. Foundations of costeffectiveness analysis for health and medical practices. New England journal of medicine 1977; 296: 716-721.

(30) Ransohoff D F, Lang C. Screening for colorectal cancer. New England journal of medicine $1991 ; 325$ : 37-41.

(31) Stason W B, Weinstein M C. Public health rounds at the Harvard School of Public Health: allocation of resources to manage hypertension. New England journal of medicine 1977; 296: 732-739.

(32) Danis M, Churchill L R. Autonomy and the common weal. Hastings Center report 1991; Jan/Feb 21, 1: 25-31.

(33) Callahan D. What kind of life: the limits of medical progress. New York: Simon and Schuster 1990: 28.

(34) Vilnius D, Dandoy S. A priority rating system for public health programs. Public health reports 1990; 105: 463 470 .

\section{News and Notes}

\section{European Bioethics Seminar: Health Care Issues in Pluralistic Societies}

The seminar will take place from May 11-15,1993 in Nijmegen, the Netherlands.

It will be conducted by scholars from a number of European nations as well as the United States. Special attention will be given to European traditions in health care ethics. The seminar is designed (1) to provide the participants with both a theoretical and a practical understanding of contemporary and pressing issues in bioethics and (2) to educate the participants on a range of topics and problems that are the focus of current debates, both within health care institutions and in society at large.

Lectures and discussion groups will be designed to attend to five principal topics: (1) foundation and history of bioethics, (2) the person: suffering and death, (3) procreation and reproduction issues, (4) ethics and community, and (5) the human body. Lectures will be in English; parallel sessions in
French and German may be offered.

The seminar is primarily directed at health care providers (for example, doctors, dentists, nurses, health lawyers, hospital administrators, bioethics committee members), and teachers in the areas of ethics, philosophy and theology. Senior students undertaking courses of study in the health professions are also invited to participate.

The seminar fee is $1.400 \mathrm{DFL}$ (approximately 625 ECU, 900US\$ or 110.000 Japanese Yen). The fee includes tuition, course materials, lunches, Wednesday and Friday dinners, and refreshments.

For information and application forms write to: $\mathrm{Dr}$ $\mathrm{J}$ Welie, Department of Ethics, Philosophy and History of Medicine, Catholic University of Nijmegen, PO Box 9101, $6500 \mathrm{HB}$ Nijmegen, the Netherlands. Tel: [31] (0)80-615320 / 617079; fax: [31] (0)80-540254. 